\title{
CEREBRAL CIRCULATION AND METABOLISM IN PULMONARY EMPHYSEMA AND FIBROSIS WITH OBSERVATIONS ON THE EFFECTS OF MILD EXERCISE ${ }^{1}$
}

\author{
By P. SCHEINBERG, I. BLACKBURN, M. SASLAW, M. RICH, AND G. BAUM
}

(From the Department of Physiology, University of Miami School of Medicine, the Department of Medicine, Veteran's Administration Hospital, Coral Gables, Fla., and the National Children's Cardiac Hospital, Miami, Fla.)

(Submitted for publication November 21, 1952; accepted February 11, 1953)

Chronic pulmonary disease, particularly emphysema and fibrosis, may result in variable alterations in blood oxygen and carbon dioxide tensions, depending upon the severity of the disease. Changes in carbon dioxide and oxygen tensions have been shown to have a profound influence on cerebral circulation in acute experiments on normal subjects (1). Recently Patterson, Heyman, and Duke (2) demonstrated that cerebral blood flow was increased above normal in a group of subjects with severe chronic pulmonary emphysema, most of whom had cor pulmonale and were in congestive heart failure. Their studies re-emphasized the importance of the influence of blood carbon dioxide and oxygen tensions on cerebral blood flow, even though the alterations in the tensions of these gases were chronic. Their patients all had advanced pulmonary disease, however, and it was felt that it would be of interest to study the effects of less severe pulmonary disease, and less profound and more variable alterations in blood gas tensions, on the cerebral physiology. Most of these patients were studied before and during moderate exercise, since mental status changes are known to occur in some patients with chronic pulmonary disease during exertion.

\section{METHODS}

Cerebral blood flow studies were carried out by means of a modification (3) of the original nitrous oxide technique (4) on 9 of 22 subjects with chronic pulmonary disease. The original nitrous oxide technique with intermittent sampling was used in the other 13 patients. Twenty of the patients had chronic pulmonary emphysema of varying severity, confirmed by history, physical examination, radiographic and fluoroscopic studies, and, in most cases,

1 This investigation was supported by research grants ( $\mathrm{H}-832$ and $\mathrm{H}-832 \mathrm{C}$ ) from the National Heart Institute of the National Institutes of Health, Public Health Service. by an estimation of maximal breathing capacity, vital capacity, and air velocity index (5). Two patients had pulmonary fibrosis without evidence of significant obstructive phenomena in the lungs, and this was confirmed by the finding of a normal air velocity index in these two subjects (S. A. and J. G., Table I). Electrocardiograms were made on all subjects but one (G. W.), and showed confirmatory evidences of cor pulmonale in 10 of the subjects. Eight of the subjects with cor pulmonale showed evidences of heart failure (though only one, C. A., was in severe failure) at the time of admission. The diagnosis of cor pulmonale in these patients was made by clinical findings, electrocardiographic changes, and chest fluoroscopy (evidences of enlargement of the right ventricular outflow tract). The patients were not studied until clinical evidences of congestive failure had disappeared on appropriate management, and none of the patients was studied during the acute stages of the illnesses which precipitated their admission, usually bronchiolar or pulmonary infections. In this way an effort was made to study each patient in a reasonably stable state, so that the possible effects of infection or heart failure would not interfere with an accurate interpretation of the results. The patients were classified for severity of pulmonary involvement according to the criteria set forth by Baldwin, Cournand, and Richards $(6,7)$.

The patients were fasting but no restrictions were placed on smoking prior to the procedure. In 12 of the subjects after the initial blood flow procedure was performed, exercise was carried out in the supine position by means of a type of exercycle attached to the foot of the table and supplied with variable resistance loads. This proved to be an unsatisfactory type of exercise, for in almost every instance the patient's legs would become tired before dyspnea appeared; many subjects who were unable to walk 50 yards without considerable dyspnea experienced little difficulty, even after performing the supine exercise for 20 to 35 minutes. The second blood flow was done after the patient had exercised for at least 10 minutes and the exercise was continued until the final blood samples were drawn. In one subject (T. K.) this exercise was sufficient to produce mild cyanosis, but none complained of severe respiratory distress, and none showed evidences of mental disturbances following exercise.

Arterial and venous oxygen contents were determined spectrophotometrically, according to the method of Hickam 
TABLE I

Clinical and pulmonary function data

\begin{tabular}{|c|c|c|c|c|c|c|}
\hline Pt. & Age & Diagnosis and comments & $\begin{array}{c}\text { Per cent } \\
\text { normal } \\
\text { maximal } \\
\text { breathing } \\
\text { capacity }\end{array}$ & $\begin{array}{c}\text { Per cent } \\
\text { normal } \\
\text { vital } \\
\text { capacity }\end{array}$ & $\begin{array}{c}\text { Air } \\
\text { velocity } \\
\text { index }\end{array}$ & $\begin{array}{l}\text { Classifi- } \\
\text { cation }\end{array}$ \\
\hline C. $\mathbf{M}$. & 59 & $\begin{array}{l}\text { Bronchial asthma, severe; pulmonary emphysema; } \\
\text { no failure on admission. }\end{array}$ & 30 & 42 & 0.72 & $I$ \\
\hline S. A. & 72 & $\begin{array}{l}\text { Tuberculosis, moderately advanced, active; pulmo- } \\
\text { nary fibrosis; no failure on admission. }\end{array}$ & 60 & 59 & 1.0 & I \\
\hline R. C. & 56 & $\begin{array}{l}\text { Chronic bronchitis, pulmonary emphysema; cor } \\
\text { pulmonale; no failure on admission. }\end{array}$ & 28 & 41 & 0.66 & IV \\
\hline S. G. & 58 & $\begin{array}{l}\text { Pulmonary emphysema ; cor pulmonale; failure on } \\
\text { admission. }\end{array}$ & 27 & 35 & 0.77 & IV \\
\hline J. G. & 55 & $\begin{array}{l}\text { Chronic bronchitis; pulmonary fibrosis; no failure } \\
\text { on admission. }\end{array}$ & 55 & 53 & 1.06 & I \\
\hline M. E. & 58 & $\begin{array}{l}\text { Pulmonary granulomatosis; cor pulmonale; failure } \\
\text { on admission. }\end{array}$ & - & - & - & IV \\
\hline L. S. & 40 & $\begin{array}{l}\text { Bronchial asthma, severe; pulmonary emphysema ; } \\
\text { no failure on admission. }\end{array}$ & 38 & 52 & 0.73 & I \\
\hline N. S. & 63 & $\begin{array}{l}\text { Pulmonary emphysema; cor pulmonale; failure on } \\
\text { admission. }\end{array}$ & 28 & 84 & 0.33 & IV \\
\hline H. J. & 54 & $\begin{array}{l}\text { Intrinsic asthma; pulmonary emphysema; no failure } \\
\text { on admission. }\end{array}$ & 35 & 64 & 0.55 & III \\
\hline W. G. & 53 & $\begin{array}{l}\text { Bronchial asthma; bronchiectasis; pulmonary em- } \\
\text { physema; cor pulmonale; failure on admission. }\end{array}$ & 38 & 49 & 0.78 & IV \\
\hline T. B. & 50 & $\begin{array}{l}\text { Pulmonary emphysema; cor pulmonale; failure on } \\
\text { admission. }\end{array}$ & 25 & 36 & 0.69 & IV \\
\hline G. W. & 41 & Pulmonary emphysema; no failure on admission. & - & - & - & II \\
\hline T. K. & 56 & $\begin{array}{l}\text { Bronchial asthma; pulmonary emphysema ; cor pul- } \\
\text { monale; no failure on admission. }\end{array}$ & - & 43 & - & II \\
\hline J. H. & 25 & $\begin{array}{l}\text { Pulmonary emphysema and fibrosis; cor pulmonale; } \\
\text { failure on admission. }\end{array}$ & 36 & - & - & IV \\
\hline C. A. & 57 & $\begin{array}{l}\text { Pulmonary emphysema; cor pulmonale; failure on } \\
\text { admission. }\end{array}$ & 24 & 56 & 0.44 & IV \\
\hline H. McD. & 63 & $\begin{array}{l}\text { Bronchial asthma; pulmonary emphysema; no fail- } \\
\text { ure on admission. }\end{array}$ & - & 43 & - & I \\
\hline G. C. & 54 & $\begin{array}{l}\text { Bronchial asthma; pulmonary emphysema ; no fail- } \\
\text { ure on admission. }\end{array}$ & 42 & 75 & 0.56 & II \\
\hline W. E. & 54 & Pulmonary emphysema; no failure on admission. & 60 & 79 & 0.76 & II \\
\hline R. S. & 47 & $\begin{array}{l}\text { Bronchial asthma; pulmonary emphysema ; no fail- } \\
\text { ure on admission. }\end{array}$ & 55 & 99 & 0.56 & II \\
\hline N. V. & 57 & $\begin{array}{l}\text { Pulmonary emphysema; cor pulmonale; failure on } \\
\text { admission. }\end{array}$ & 21 & 36 & 0.58 & IV \\
\hline C. $\mathbf{K}$. & 55 & Bullous emphysema; no failure on admission. & - & - & - & III \\
\hline L. $\mathbf{S}$. & 74 & $\begin{array}{l}\text { Bronchial asthma; pulmonary emphysema ; no fail- } \\
\text { ure on admission. }\end{array}$ & - & - & 一 & II \\
\hline
\end{tabular}

and Frayser (8). Blood samples for oxygen determination were drawn before and after each blood flow measurement, and the average was used as the final value for arterial-cerebral venous oxygen difference and arterial oxygen saturation. Carbon dioxide determinations were carried out on the van Slyke-Neill manometric apparatus, as described by Peters and van Slyke (9). Arterial blood pressure was recorded at heart level by the auscultatory method at intervals of approximately two minutes, and mean pressure calculated from the formula: $M P=$ diastolic pressure $+1 / 3$ pulse pressure. The calculated mean pressures checked closely with mean pressures measured directly by means of a mercury U-tube manometer.

pH measurements were made with the Model $\mathrm{R}$ Cambridge $\mathrm{pH}$ meter. Blood was drawn into heparin-coated syringes and immediately transferred to a constant temperature room at $33-34^{\circ} \mathrm{C}$. The syringes were allowed to stand for three to six minutes to allow the temperature to fall from body temperature to the temperature of the room before readings were made. Buffers at $\mathrm{pH} 4.00$ (acid phthalate) and 6.99 (phosphate) were used to check the instrument for standardization. The Rosenthal factor was used to correct the readings to $38^{\circ} \mathrm{C}$. (10). Arterial and venous oxygen tensions were estimated from the $\mathrm{pH}$ and the per cent oxyhemoglobin saturation, using the dissociation curves of Dill. The values for oxygen tension when oxyhemoglobin saturation was above 90 per cent were obtained from a chart of interpolated values, using Dill's figures, since it was impossible to read the curves accurately above this point. Carbon dioxide ten- 


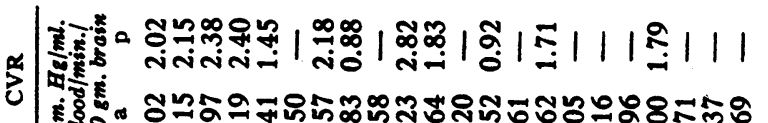

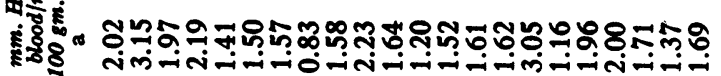

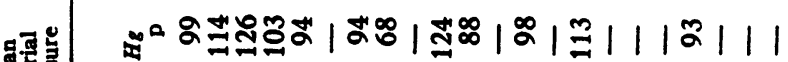
เ

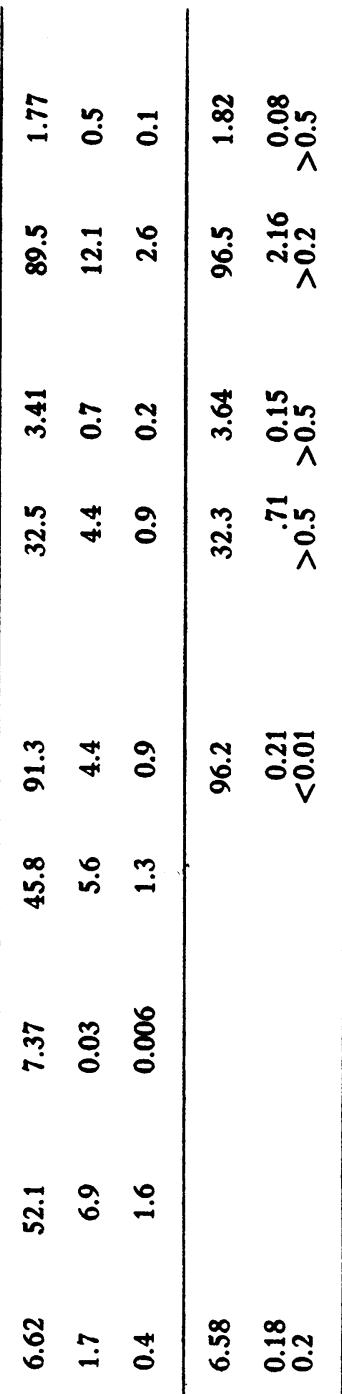

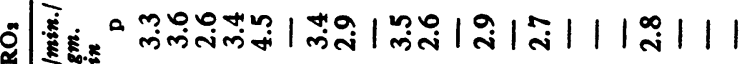
है. $\vec{E}$

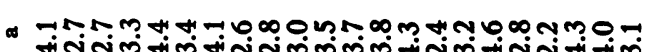

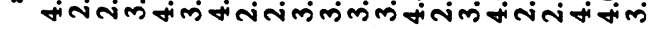

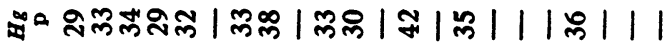

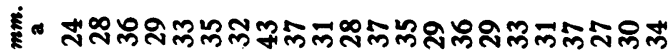

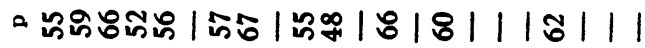

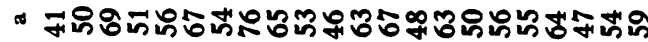

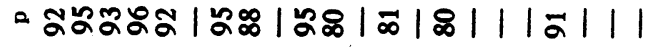

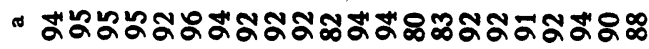

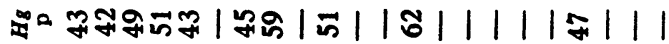

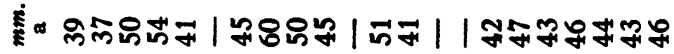

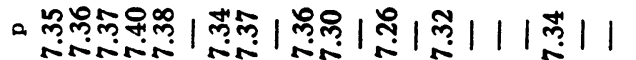

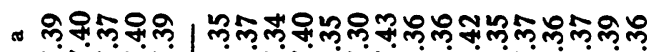

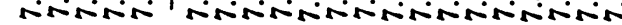

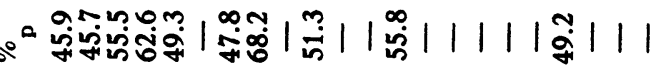

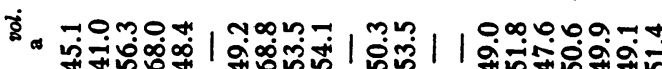

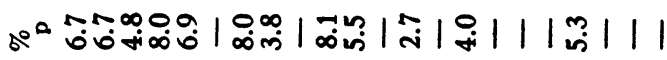

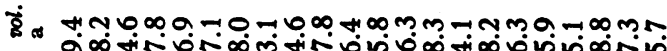

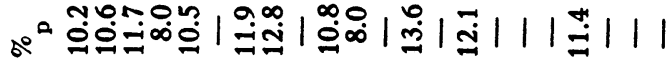

ส

i̊

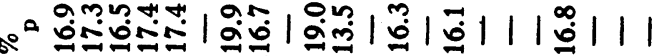

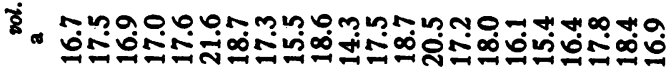

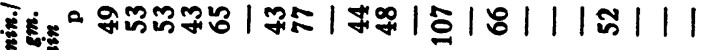
हैं

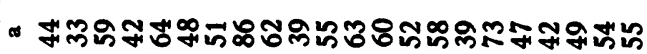

종요

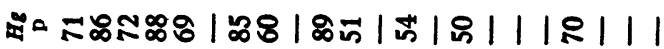

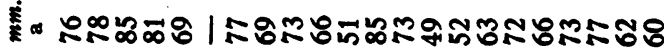


sions were estimated from the nomograms of Peters and van Slyke (9).

\section{RESULTS}

Comparison with normal subjects. A clinical summation of the patients is given in Table $\mathrm{I}$, and the results of the studies are given in detail in Table II. The patients ranged in age from 25 to 74 years, with an average of 55 years. They were compared with a group of 32 normal subjects who ranged in age from 38 to 79 years, averaging 56 years (11). It was felt necessary to compare the subjects with others in a similar age group, as definite changes in cerebral circulation and metabolism accompany advancing age (11). There was no significant alteration in cerebral blood flow, arterial-cerebral venous $\mathrm{O}_{2}$ difference, cerebral $\mathrm{O}_{2}$ consumption, or cerebral vascular resistance (Table II).

The blood gas tensions indicate that the chemical effects of pulmonary disease in most of these patients were not extensive. Only five of the patients had values for $\mathrm{PCO}_{2}$ of $50 \mathrm{~mm}$. $\mathrm{Hg}$ or above ; however, $\mathrm{pCO}_{2}$ determinations were not obtained in the three patients with the lowest arterial $\mathrm{O}_{2}$ saturation and tensions because of technical error. Were these figures available, it is possible that a much higher mean for $\mathrm{pCO}_{2}$ would have been obtained, but even so the mean value for cerebral blood flow is within normal limits. Arterial $\mathrm{pH}$ did not differ significantly from the normal, and mean per cent arterial oxygen saturation was 91.3, both indications that this group represents relatively mild, or at least well-compensated pulmonary disease.

If the subjects are divided into two groups according to clinical severity of their disease, by contrasting those subjects in group I and II with those in groups III and IV, there are no significant differences observed in cerebral blood flow, cerebral oxygen consumption, and arterial $\mathrm{pH}$ between the two groups. Since the clinical classification is itself partially dependent upon arterial $\mathrm{pO}_{2}$ and $\mathrm{pCO}_{2}$ values, the value for $\mathrm{pO}_{2}$ is significantly lower and that for $\mathrm{pCO}_{2}$ higher in the second

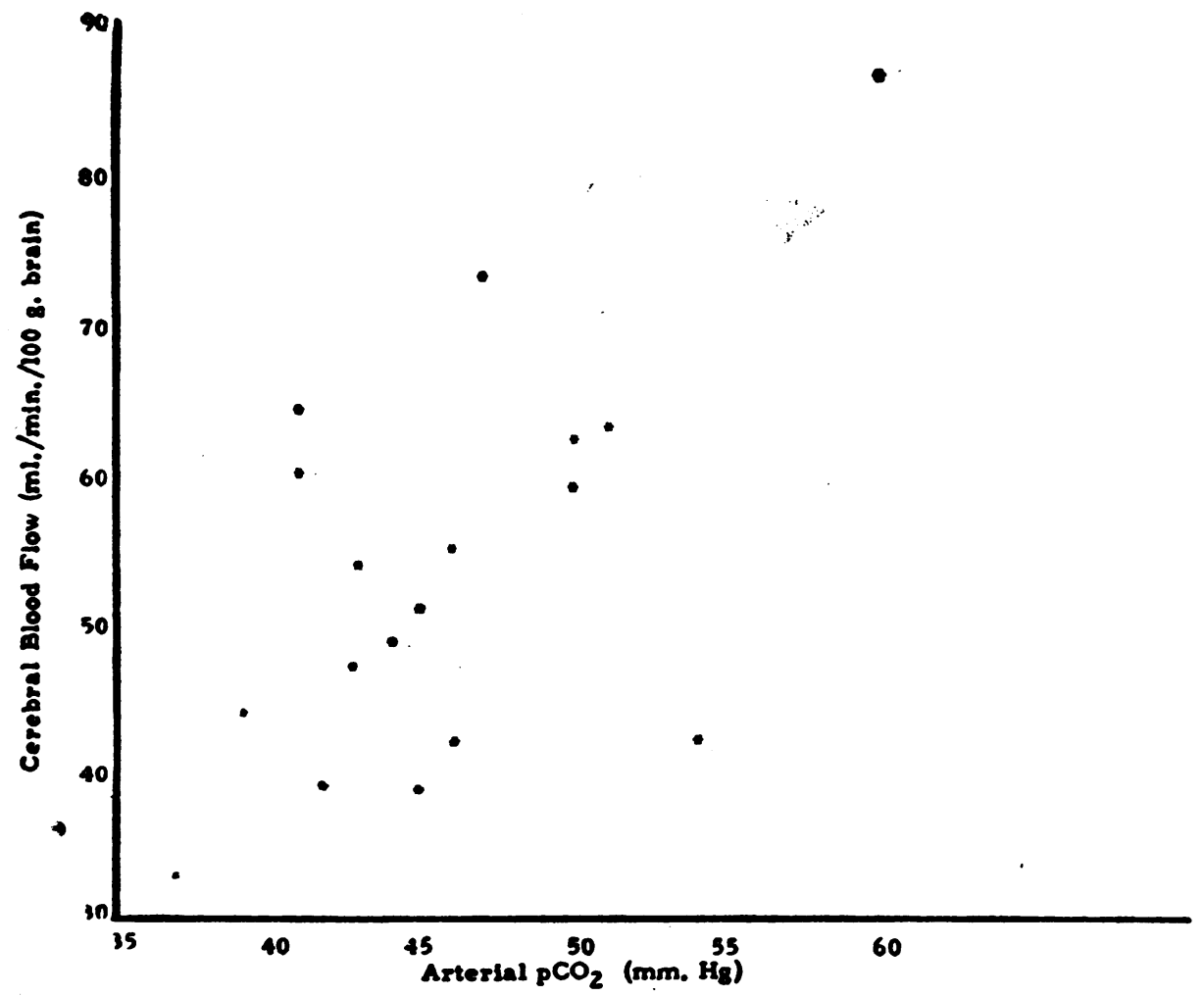

Fig. 1. Correlation between Arterial $\mathrm{PCO}_{2}$ and $\mathrm{CBF}$

$$
r=0.63 \quad p<0.01
$$




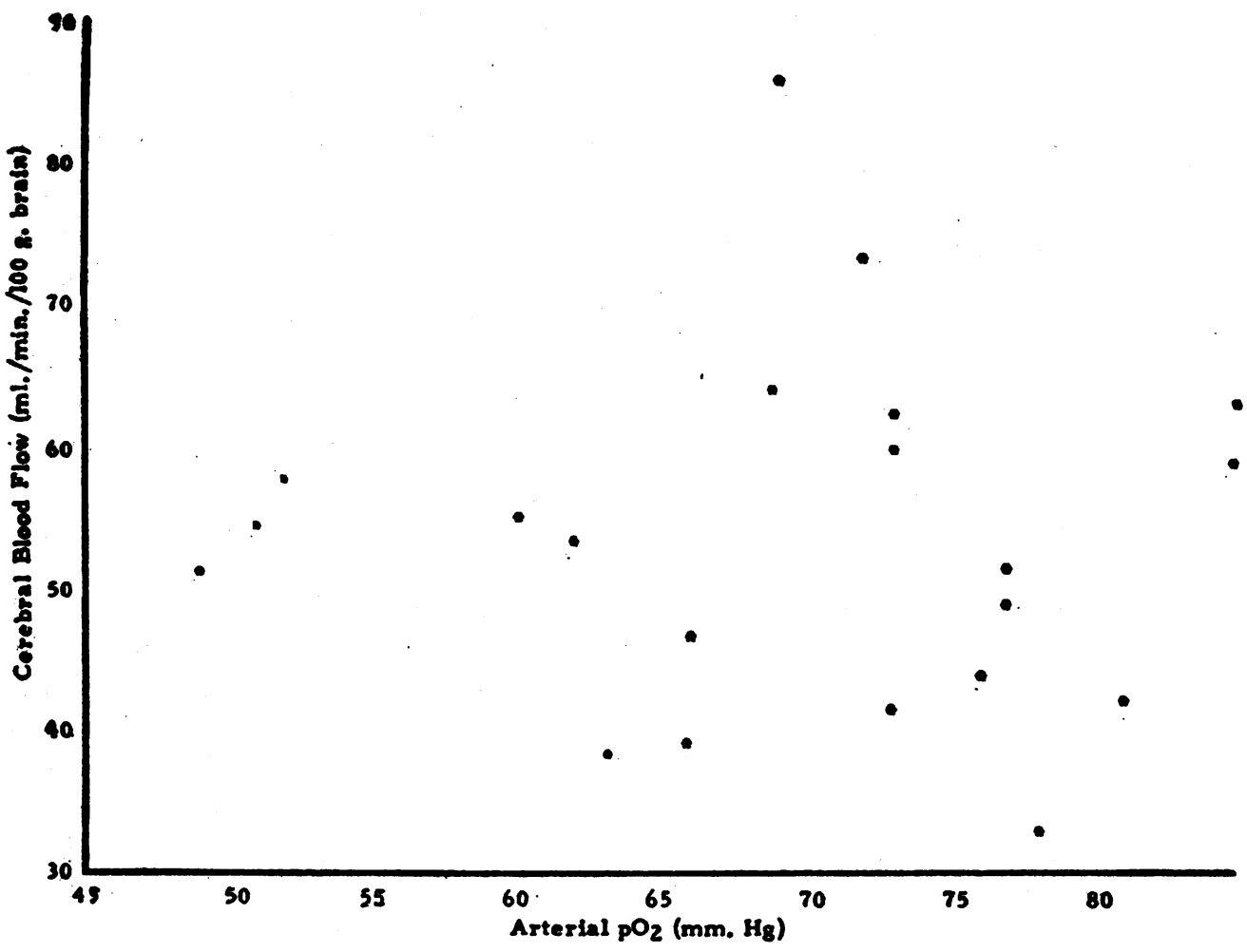

Fig. 2. Correlation between Arterial $\mathrm{PO}_{2}$ and CBF

$$
r=0.03
$$

group than in the first. When considering all the patients together, however, there is an adequate correlation between arterial $\mathrm{pCO}_{2}$ and cerebral blood flow and no correlation between arterial $\mathrm{pO}_{2}$ and cerebral blood flow (Figures 1 and 2). There

TABLE III

Effects of mild exercise on cerebral metabolic functions (mean values in 12 subjects)

\begin{tabular}{|c|c|c|c|}
\hline & $\begin{array}{c}\text { Before } \\
\text { exercise }\end{array}$ & $\begin{array}{c}\text { During } \\
\text { exercise }\end{array}$ & $p$ value \\
\hline $\begin{array}{l}\text { Art. } \mathrm{pO}_{2} \\
\text { CBF } \\
\text { Art. } \mathrm{O}_{2} \text { content } \\
\text { Venous } \mathrm{O}_{2} \text { content } \\
\text { A-V } \mathrm{O}_{2} \\
\text { Art. } \mathrm{CO}_{2} \text { content } \\
\text { Venous } \mathrm{CO}_{2} \text { content } \\
\text { Art. pH } \\
\text { Art. pCO } \\
\text { Venous pCO } \\
\text { Per cent art. } \mathrm{O}_{2} \text { sat. } \\
\text { Per cent venous } \mathrm{O}_{2} \text { sat. } \\
\text { Venous pO } \\
\text { CMRO } \\
\text { MAP } \\
\text { CVR }\end{array}$ & $\begin{array}{l}70.8 \\
52.8 \\
17.2 \\
10.8 \\
6.48 \\
53.5 \\
54.7 \\
7.38 \\
45.8 \\
50.1 \\
91.7 \\
57.5 \\
32.7 \\
3.23 \\
90.7 \\
1.85\end{array}$ & $\begin{array}{c}70.4 \\
58.3 \\
17.0 \\
11.0 \\
5.88 \\
53.1 \\
54.2 \\
7.34 \\
49.2 \\
51.1 \\
89.8 \\
58.6 \\
33.7 \\
3.18 \\
101.2 \\
1.88\end{array}$ & $\begin{array}{l}>0.5 \\
>0.2 \\
>0.5 \\
>0.5 \\
>0.1 \\
>0.5 \\
>0.5 \\
<0.02^{*} \\
>0.2 \\
>0.5 \\
>0.2 \\
>0.5 \\
>0.05 \\
>0.5 \\
<0.01 * \\
>0.5\end{array}$ \\
\hline
\end{tabular}

\footnotetext{
* Denotes statistically significant change.
}

is also no correlation between cerebral blood flow and clinical severity of the ventilatory defect as expressed by reduction in percentage normal maximal breathing capacity.

Effects of exercise. The effects of exercise on the 12 subjects in whom it was studied are summarized in Table III. The only statistically significant changes were the drop in arterial $\mathrm{pH}$ from 7.38 to 7.34 and the increase in mean arterial pressure. It is of interest that the only two subjects who showed a considerable rise in cerebral blood flow during exercise also had a sizable increase in $\mathrm{pCO}_{2}$ (S. A. and T. K., Table II), although two other subjects showed some increase in $\mathrm{pCO}_{2}$ without accompanying significant elevation of cerebral blood flow. There is no evidence of even a trend toward an increase in cerebral blood flow or decrease in arterial-cerebral venous $\mathrm{O}_{2}$ difference during exercise, for the changes were quite variable, and only one patient ( $T$. K.) was actually responsible for the apparent change in the mean values of these functions. Cerebral oxygen consumption and cerebral vascular resistance were. 
not altered by exercise, although there was a fairly consistent increase in mean arterial pressure. There was no consistent change in per cent arterial $\mathrm{O}_{2}$ saturation or arterial $\mathrm{pO}_{2}$, the only striking reduction in either occurring in T. K. This is further evidence of the relative mildness of this type of exercise or the relative lack of severity of pulmonary disease in these patients, or both.

Pulmonary fibrosis. The two patients with pulmonary fibrosis showed no differences in cerebral metabolic functions from the patients with emphysema.

Intermittent vs. continuous sampling techniques. There was no significant difference in any of the cerebral metabolic functions in the nine subjects studied by the continuous sampling technique as compared to the 13 studied by the original intermittent sampling technique, as seen in Table IV, and for that reason both groups were combined for final statistical analysis in this study. The studies were done by both techniques as a part of planned observations to determine the possible
TABLE IV

Comparison of intermittent and continuous sampling techniques (mean values)

\section{CBF}

CMRO

CVR

$\begin{array}{cc}\begin{array}{c}\text { Intermittent } \\ \text { (13 subjects) }\end{array} & \begin{array}{c}\text { Continuous } \\ \text { (9 subjects) }\end{array} \\ 57 & 51 \\ 3.3 & 3.5 \\ 1.69 & 1.89\end{array}$

All $\mathrm{p}$ values $>0.3$.

reason for the differences in mean values in normal subjects as reported by Kety and Schmidt (4), Scheinberg and Stead (3) and Patterson, Heyman, and Nichols (12). In this group of subjects, at least, there is no significant difference between results obtained by the two techniques.

Electroencephalograms. Electroencephalograms performed on eight of the subjects were all within normal limits.

\section{DISCUSSION}

The data reported here cannot be compared with the observations on cerebral circulatory functions in pulmonary emphysema reported by Pat-

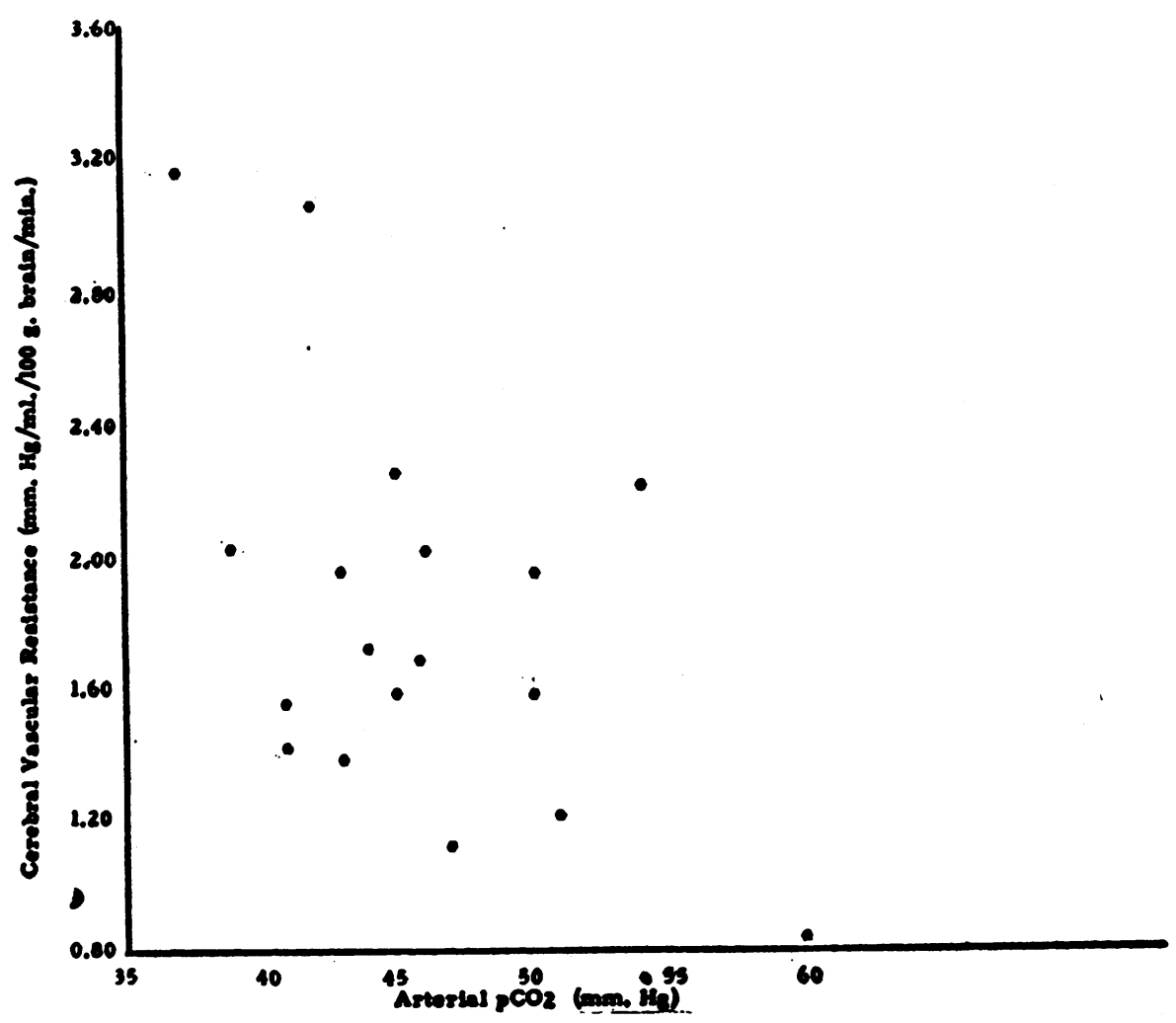

Fig. 3. Correlation between CVR and Arterial pCO,

$$
r=0.51 \quad 0.05>p>0.01
$$




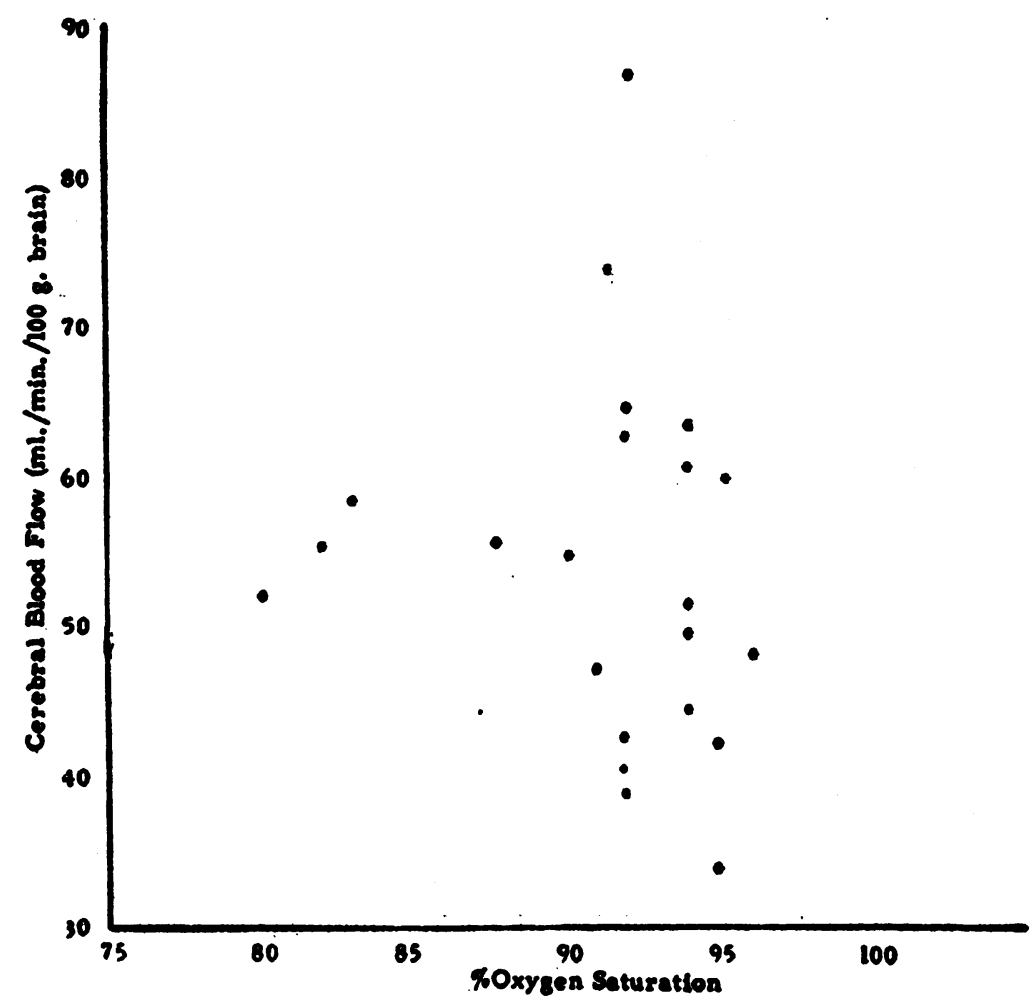

Fig. 4. Correlation between Per Cent Oxygen Saturation and CBF

$$
r=0.03
$$

terson, Heyman, and Duke (2), since most of our subjects suffered less pulmonary disability than did theirs. In both groups of subjects there was adequate correlation between cerebral blood flow and $\mathrm{pCO}_{2}$, and cerebral vascular resistance and $\mathrm{pCO}_{2}$. In our subjects the $\mathrm{p}$ values for these correlations were $<0.01$ and between 0.01 and 0.05 , respectively (Figures 1 and 3 ). We found no correlation, however, between $\mathrm{pO}_{2}$ and cerebral blood flow or between per cent arterial $\mathrm{O}_{2}$ saturation and cerebral blood flow (Figures 2 and 4), and we are unable to explain this discrepancy. Our patients were not studied until the effects of the acute illnesses which precipitated admission to the hospital had subsided and the patients were reasonably stable. Patterson, Heyman, and Duke make no statement concerning whether this precaution was observed in their group. In addition five of the nine patients they reported had evidence of congestive heart failure due to cor pulmonale. Since this type of failure reportedly is accompanied frequently by an increased cardiac output (13), there is a possibility that the failure itself rather than pulmonary emphysema may be responsible for the elevated cerebral blood flow in these subjects. Two of their subjects had low and normal cardiac indices ( $\mathrm{T}-1824$ dye), however, making such an explanation dubious without further investigation.

The correlation between cerebral blood flow and $\mathrm{pCO}_{2}$ in our subjects confirms previous observations on the effects of inspired $\mathrm{CO}_{2}$ on cerebral circulation (1), and the normal mean value for cerebral blood flow obtained in this group is compatible with an essentially normal mean value for $\mathrm{pCO}_{2}$. The absence of correlation between cerebral blood flow and arterial $\mathrm{pO}_{2}$ is surprising, as is the apparent absence of effect of a decreased mean value for arterial $\mathrm{pO}_{2}$ in the whole group. Previous observations (1) have indicated that a decrease in $\mathrm{pO}_{2}$ is a fair stimulus for producing cerebral vasodilatation in normal subjects; perhaps the absence of this phenomenon in the group of subjects reported here indicates the development of a tolerance and diminished response to the cerebral vasodilating effect of a low oxygen environ- 
ment if the oxygen deprivation is chronic rather than acute.

Little was learned about the effects of exercise in this study, except that patients with only moderately severe functional pulmonary disability have a remarkable tolerance to this type of exercise. One might anticipate an increase in cerebral blood flow to accompany a rise in arterial $\mathrm{pCO}_{2}$ in those patients whose limitation of ventilatory capacity prevents compensatory hyperventilation, and such seemed to be the case in the two subjects who showed the most striking chemical responses to exercise. It is of interest that the reduction in arterial $\mathrm{pH}$ during exercise was not associated with a change in cerebral blood flow. This is further evidence that alteration in arterial $\mathrm{pH}$ per se is not the important factor in the regulation of cerebral blood flow (14). Since none of our subjects developed signs of mental confusion during this relatively mild exertion, one of the purposes of this study, which was to investigate the physiological basis for the confusion which occurs during physical exertion in many such patients, was not achieved.

These studies verify the previously established relationship between arterial $\mathrm{pCO}_{2}$ and cerebral blood flow and demonstrate a relative lack of importance of individual changes in arterial $\mathrm{pH}$, arterial $\mathrm{pO}_{2}$, and arterial $\mathrm{CO}_{2}$ content in the regulation of cerebral circulation. They also demonstrate that cerebral vascular and metabolic functions in chronic pulmonary diseases are unrelated to the severity of the clinical and spirometric disturbance, but are rather related to alteration in gaseous exchange in the lungs, and specifically to carbon dioxide retention.

\section{SUMMARY}

1. Cerebral blood flow, oxygen consumption, and vascular resistance were measured in 22 patients with chronic pulmonary disease of moderate functional severity, and compared with a group of normal controls of the same average age. The effects of mild exercise were studied in 12 of the patients.

2. There was no significant difference in cerebral blood flow as measured by the intermittent sampling technique in 13 of these subjects as compared to the continuous sampling technique in the remaining nine subjects.

3. Mean values for cerebral blood flow, cerebral A-V $\mathrm{O}_{2}$ difference, cerebral oxygen consumption, and cerebral vascular resistance did not differ significantly from the normal control subjects.

4. The correlation between cerebral blood flow and arterial $\mathrm{pCO}_{2}$ was good, whereas no correlation was found between cerebral blood flow and arterial $\mathrm{pO}_{2}$ or per cent arterial $\mathrm{O}_{2}$ saturation.

5. The effects of exercise on cerebral metabolic functions in these patients were variable and without a significant trend. A reduction in arterial $\mathrm{pH}$ during exercise did not influence cerebrat blood flow.

6. These studies re-emphasize the important relationship between arterial $\mathrm{pCO}_{2}$ and cerebral blood flow and demonstrate the relative unimportance of the clinical and spirometric severity classification on cerebral blood flow in chronic pulmonary disease.

\section{ACKNOWLEDGMENT}

The authors gratefully acknowledge the technical assistance of Mrs. Janet Fetner.

\section{REFERENCES}

1. Kety, S. S., and Schmidt, C. F., The effects of altered arterial tensions of carbon dioxide and oxygen on cerebral blood flow and cerebral oxygen consumption of normal young men. J. Clin. Invest., 1948, 27, 484.

2. Patterson, J. L., Jr., Heyman, A., and Duke, T. W., Cerebral circulation and metabolism in chronic pulmonary emphysema. With observations on the effects of inhalation of oxygen. Am. J. Med., 1952, 12, 382.

3. Scheinberg, P., and Stead, E. A., Jr., The cerebral blood flow in normal male subjects as measured by the nitrous oxide technique. Normal values for blood flow, oxygen utilization, glucose utilization and peripheral resistance, with observations on the effect of tilting and anxiety. J. Clin. Invest., 1949, 28, 1163.

4. Kety, S. S., and Schmidt, C. F., The nitrous oxide methods for the determination of cerebral blood flow in man: Theory, procedure and normal values. J. Clin. Invest., 1948, $27,476$.

5. Gaensler, E. G., Air velocity index. A numerical expression of the functionally effective portion of ventilation. Am. Rev. Tuberc., 1950, 62, 17. 
6. Baldwin, E. de F., Cournand, A., and Richards, D. W., Jr., Pulmonary insufficiency. I. Physiological classification, clinical methods of analysis, standard values in normal subjects. Medicine, 1948, 27, 243.

7. Baldwin, E. de F., Cournand, A., and Richards, D. W., Jr., Pulmonary insufficiency. III. A study of 122 cases of chronic pulmonary emphysema. Medicine, 1949, 28, 201.

8. Hickam, J. B., and Frayser, R., A spectrophotometric method for determining blood oxygen. J. Biol. Chem., 1949, 180, 457.

9. Peters, J. P., and van Slyke, D. D., Quantitative Clinical Chemistry, Vol. II, Methods. Williams \& Wilkins, Baltimore, 1932.

10. Rosenthal, T. B., The effect of temperature on the
$\mathrm{pH}$ of blood and plasma in vitro. J. Biol. Chem., 1948, 173, 25.

11. Scheinberg, P., Blackburn, I., Rich, M., and Saslaw, M., The effects of aging on cerebral circulation and metabolism. In manuscript.

12. Patterson, J. L., Jr., Heyman, A., and Nichols, F. T., Jr., Cerebral blood flow and oxygen consumption in neurosyphilis. J. Clin. Invest., 1950, 29, 1327.

13. Harvey, R. M., Ferrer, I., Richards, D. W., Jr., and Cournand, A., Influence of chronic pulmonary disease on the heart and circulation. Am. J. Med., $1951,10,719$.

14. Schieve, J. F., and Wilson, W. P., The changes in cerebral vascular tone in experimental metabolic alkalosis and acidosis. J. Clin. Invest., 1952, 31, 659. 